\title{
INTEGRATED SURFACE WATER-GROUNDWATER MODELLING
}

\author{
K. SPANOUDAKI ${ }^{1}$ \\ A. NANOU ${ }^{1}$ \\ A.I. STAMOU ${ }^{1}$ \\ G. CHRISTODOULOU ${ }^{1}$ \\ T. SPARKS ${ }^{2}$ \\ B. BOCKELMANN ${ }^{2}$ \\ R.A. FALCONER ${ }^{2}$
}

\author{
${ }^{1}$ Laboratory of Applied Hydraulics, Department of Water Resources \\ Hydraulic and Maritime Engineering, School of Civil Engineering \\ National Technical University of Athens \\ Iroon Polytechniou 5, 15780 Athens, Greece \\ ${ }^{2}$ Hydroenvironmental Research Centre \\ School of Civil Engineering \\ Cardiff University, Wales, UK
}

Selected from papers presented in $9^{\text {th }}$ International Conference on Environmental Science and Technology (9CEST2005)

1-3 September 2005, Rhodes island, Greece

\begin{abstract}
Two Integrated Surface water - Groundwater flow Models (ISGMs) have been developed at the National Technical University of Athens (NTUA), Greece and Cardiff University (CU), UK to investigate surface water-groundwater interactions. The models are based on physical processes and are capable of describing more accurately the recharge and discharge flow paths between surface and ground waters.

The NTUA ISGM consists of a 3-D surface water flow sub-model (FLOW-3DL) and a 3-D saturated groundwater flow sub-model. The CU ISGM is based on the 2-D surface water model DIVAST, which has been extended to include 2-D saturated groundwater flow. Both models use the finite difference method and orthogonal grids. The momentum and mass conservation equations are the governing equations for both surface and groundwater flows.

The ISGMs have been applied to two simple cases and their results have been compared to computations using only surface water models (FLOW-3DL and DIVAST) to demonstrate the need to use ISGMs for accurate and satisfactory calculations. Furthermore, the results of the two ISGMs are compared for a channel, which fully penetrates an aquifer. The two ISGMs show a similar behaviour; the NTUA ISGM exhibits a slightly slower response of the aquifer water levels to the water level changes in the channel than the CU ISGM.
\end{abstract}

KEYWORDS: integrated modelling, stream-aquifer interactions, surface water, groundwater

\section{INTRODUCTION}

Historically, surface water and ground water models have been developed separately as two individual entities. The interaction between them is usually taken into account as a boundary condition in groundwater modelling, while it is ignored in surface water modelling. However, there are many water resources problems that require a more realistic linkage between surface water and groundwater. Understanding how surface water levels are related to adjacent aquifer systems is important for example, for the management of wetlands and river habitat restoration. Pollution of groundwater may influence surface water resources and vice versa. Whether a river floods at times of heavy rain or not will often depend on the surrounding groundwater levels. For these 
situations it is desirable to consider surface and ground water as interconnected and to develop tools to describe the interactions between the two.

There have been a number of models that attempt to simulate the interactions between surface water and groundwater. Many of these models, such as ModBranch [1], the Wetland Modflow module [2] and Daflow-Modflow [3], are based on the linking of surface water models with the groundwater model MODFLOW [4].

Considering the degree of coupling between the surface and groundwater components of Integrated Surface water-Groundwater Models (ISGMs), the highest level is to numerically solve all the equations for the surface water flow, the groundwater flow and the common internal boundary condition between the two as a set of simultaneous equations for each time step. Only a few studies [5 and 6] are reported in the literature on this approach.

The next level of coupling is to solve the surface and groundwater flow equations separately but iteratively at the same time step, interlinked by a common internal boundary condition representing the exchange between the surface and groundwater flows [ 1 and 7]. Solution for the surface and groundwater flows at a time step is achieved when the iteration errors fall within specified tolerances before the computation is advanced to the next time step.

The third integrated modelling approach, which is the simplest, but also the least accurate, is by solving the surface flow equations and subsurface flow equations in succession without iteration [3, 8 and 9].

Most investigators of integrated surface water-groundwater modelling have used surface models, which are limited either to 1-D stream flow [1 and 10] or to 2-D overland flow [9 and 7]. In these models, 2-D or 3-D variably saturated groundwater flow is considered.

To our knowledge, there is no ISGM available, which considers 3-D surface and 3-D groundwater flow while there are very few 2-D ISGMs available in the non-commercial domain. In the framework of the bi-lateral project "Development and Application of an Integrated Hydro-informatics Software Tool for Flow and Pollutant Interactions between the Coastal Zone and Neighbouring Wetlands" between Greece and Great-Britain, two ISGMs have been developed by the Greek and British research teams at NTUA and Cardiff University respectively and are described in the present paper.

\section{THE MATHEMATICAL MODELS}

The ISGMs are based on the 3-D surface water model FLOW-3DL [11] developed at NTUA and the 2-D surface water model DIVAST [12] developed at CU. FLOW-3DL and DIVAST are developed to simulate hydrodynamics and water quality in estuarine and coastal waters. Both models use the finite difference method and orthogonal grids.

These models have been extended to include the groundwater equations for porous media in order to simulate interactions between surface and groundwater systems.

The momentum and mass conservation equations are the governing equations for both surface and groundwater flows; with the momentum equation essentially being given by Darcy's law for groundwater.

The two ISGMs are described in the following paragraphs. The governing equations of the two models are shown in Table 1.

\subsection{The equations of the surface water models}

The equations of FLOW-3DL are the 3-D, non-steady state continuity (1a) and momentum (2a, $3 a$ and $4 a$ ) equations, expressed in layer formulation and assuming that the pressure is hydrostatic. The variables of the model are the layer averaged velocity components $\mathrm{u}, \mathrm{v}$ and $\mathrm{w}[\mathrm{L} / \mathrm{T}]$ along the $\mathrm{x}, \mathrm{y}$ and $\mathrm{z}$ axes, respectively, of a Cartesian coordinate system and the free surface elevation $\zeta[L]$ relative to the initial surface water level $z_{s i}[L] ; t$ is the time $[T], v_{t}\left[L^{2} / T\right]$ is the eddy viscosity coefficient, $g\left[L / T^{2}\right]$ is the gravitational acceleration, $p$ is the pressure $\left[M / L^{*} T^{2}\right], \rho$ is the density of water $\left[M / L^{3}\right]$ and $\mathrm{H}_{\mathrm{k}}[\mathrm{L}]$ is the depth of layer with index $\mathrm{k}$. 
Although the pressure is assumed hydrostatic, the vertical velocity component $w$ is estimated from the continuity equation (1a). At the surface layer, equation (1a) can be written as a boundary condition to determine the surface elevation $\zeta$ given by equation (5a) where ' $s$ ' denotes the values at the free surface; $q_{x s}$ or $u_{s}\left[L^{2} / T\right]$ is the flow per unit width in the $x$-direction, $q_{y s}$ or $\mathrm{vH}_{\mathrm{s}}\left[\mathrm{L}^{2} / \mathrm{T}\right]$ is the flow per unit width in the $y$-direction and $\mathrm{H}_{\mathrm{s}}$ $[L]$ is the depth of the surface layer.

The equations of DIVAST are the depth-integrated continuity (1b) and momentum (2b and $3 \mathrm{~b}$ ) equations, often referred to as the 'Shallow Water Equations' (SWEs). The momentum equations (2b) and (3b) are the depth-integrated form of equations (2a) and (3a), respectively. The variables of the model are the flow per unit width $q_{x}$ or $U H\left[L^{2} / T\right]$ and $\mathrm{q}_{\mathrm{y}}$ or $\mathrm{VH}\left[\mathrm{L}^{2} / \mathrm{T}\right]$ in the $\mathrm{x}$ and $\mathrm{y}$ directions respectively and the free surface elevation $\zeta$ $[\mathrm{L}] ; \mathrm{U}[\mathrm{L} / \mathrm{T}]$ and $\mathrm{V}[\mathrm{L} / \mathrm{T}]$ are the depth-averaged velocity components in the $\mathrm{x}$ and $\mathrm{y}$ directions, respectively; $H[L]$ is the depth of the water column and $\beta$ is the momentum correction factor to correct for non-uniform velocity distribution.

The surface wind stresses $T_{s x}, T_{s y}\left[M / L^{*} T^{2}\right]$ and the bed friction $T_{b x}, T_{b y}\left[M / L^{*} T^{2}\right]$ for the $x$ and $y$ directions, respectively, are given by the following equations:

$$
\begin{array}{ll}
\tau_{\mathrm{sx}}=\mathrm{C}_{\mathrm{s}} \rho_{\alpha} \mathrm{W}_{\mathrm{x}} \sqrt{\mathrm{W}_{\mathrm{x}}^{2}+\mathrm{W}_{\mathrm{y}}^{2}} & \text { and } \tau_{\mathrm{sy}}=\mathrm{C}_{\mathrm{s}} \rho_{\alpha} \mathrm{W}_{\mathrm{y}} \sqrt{\mathrm{W}_{\mathrm{x}}^{2}+\mathrm{W}_{\mathrm{y}}^{2}} \\
\tau_{\mathrm{bx}}=\frac{\rho g}{\mathrm{C}^{2}} \mathrm{u}_{\mathrm{b}} \sqrt{\mathrm{ub}_{\mathrm{b}}^{2}+\mathrm{v}_{\mathrm{b}}^{2}} \text { and } & \tau_{\mathrm{by}}=\frac{\rho g}{\mathrm{C}^{2}} \mathrm{v}_{\mathrm{b}} \sqrt{\mathrm{ub}_{\mathrm{b}}^{2}+\mathrm{v}_{\mathrm{b}}^{2}} \text { for FLOW-3DL } \\
\tau_{\mathrm{bx}}=\frac{\rho g}{\mathrm{C}^{2}} \mathrm{U} \sqrt{\mathrm{U}^{2}+\mathrm{V}^{2}} \text { and } & \tau_{\mathrm{by}}=\frac{\rho g}{\mathrm{C}^{2}} \mathrm{~V} \sqrt{\mathrm{U}^{2}+\mathrm{V}^{2}} \text { for DIVAST }
\end{array}
$$

In FLOW-3DL either a constant value or a one-equation turbulence model proposed by Koutitas [13] can be used for $v_{t}$, while in DIVAST a constant value is assumed for the depth-integrated value of $v_{t}$. In FLOW-3DL the cross-terms of the turbulent shear stresses are omitted.

\subsection{The equations of the ground water models}

The NTUA ISGM uses the equations for 3-D groundwater flow through a saturated porous medium, which are the continuity equation (5a) and Darcy's law written for the $x, y$ and $z$ directions of a Cartesian coordinate system (equations $6 a, 7 a$ and $8 a$ ). The variables of the model are the groundwater velocity components $u_{p}, v_{p}$ and $w_{p}[L / T]$ along the $x, y$ and $z$ axes, respectively and the piezometric head $h$ [L].

In equations $(6 a)$ to $(9 a) Q\left[T^{-1}\right]$ is a volumetric flux per unit volume and represents sinks/sources of water, $\mathrm{S}_{\mathrm{s}}\left[\mathrm{L}^{-1}\right]$ is the specific storage of the porous media and $\mathrm{K}_{\mathrm{xx}}, \mathrm{K}_{\mathrm{yy}}$ and $\mathrm{K}_{\mathrm{zz}}[\mathrm{L} / \mathrm{T}]$ are the values of hydraulic conductivity along the $\mathrm{x}, \mathrm{y}$ and $\mathrm{z}$ axes respectively, which are assumed to be parallel to the major axes of hydraulic conductivity. The corresponding equations for the CU ISGM are the 2-D continuity equation (6b) and Darcy's law written for the $x$ and $y$ directions (equations $7 b$ and $8 b$ ), which are shown in Table 1. The variables of the model are the discharges per unit width $q_{x}$ and $q_{y}$ in the $x$ and $y$ directions respectively and the piezometric head $h . K[L / T]$ is the hydraulic conductivity of the porous medium and $\mathrm{n}$ is the porosity.

\subsection{The solution method for the NTUA ISGM}

The piezometric head for any given surface water or groundwater cell is a function of pressure as:

$$
h=z+\frac{p}{\rho g}
$$


Table 1. Governing equations of the ISGMs

\begin{tabular}{|c|c|}
\hline The NTUA ISGM & The CU ISGM \\
\hline $\begin{array}{l}\text { Continuity equation } \\
\frac{\partial \mathrm{u}}{\partial \mathrm{x}}+\frac{\partial \mathrm{v}}{\partial \mathrm{y}}+\frac{\partial \mathrm{w}}{\partial \mathrm{z}}=0 \\
\frac{\partial \zeta}{\partial \mathrm{t}}+\frac{\partial \mathrm{q}_{\mathrm{xs}}}{\partial \mathrm{x}}+\frac{\partial \mathrm{q}_{\mathrm{ys}}}{\partial \mathrm{y}}=\mathrm{w}_{\mathrm{s}}\end{array}$ & $\begin{array}{l}\text { Continuity equation } \\
\frac{\partial \zeta}{\partial \mathrm{t}}+\frac{\partial \mathrm{q}_{\mathrm{x}}}{\partial \mathrm{y}}+\frac{\partial \mathrm{q}_{\mathrm{y}}}{\partial \mathrm{z}}=0\end{array}$ \\
\hline $\begin{array}{l}\text { Momentum equation in } \mathrm{x} \text { direction } \\
\frac{\partial \mathrm{u}}{\partial \mathrm{t}}+\mathrm{u} \frac{\partial \mathrm{u}}{\partial \mathrm{x}}+\mathrm{v} \frac{\partial \mathrm{u}}{\partial \mathrm{y}}+\mathrm{w} \frac{\partial \mathrm{u}}{\partial \mathrm{z}}=-\mathrm{g} \frac{\partial \zeta}{\partial \mathrm{x}}+ \\
+\frac{\partial}{\partial \mathrm{x}}\left[\mathrm{v}_{\mathrm{t}} \frac{\partial \mathrm{u}}{\partial \mathrm{x}}\right]+\frac{\partial}{\partial \mathrm{y}}\left[\mathrm{v}_{\mathrm{t}} \frac{\partial \mathrm{u}}{\partial \mathrm{y}}\right]+ \\
+\frac{\partial}{\partial \mathrm{z}}\left[\mathrm{v}_{\mathrm{t}} \frac{\partial \mathrm{u}}{\partial \mathrm{z}}\right]+\frac{\tau_{\mathrm{sx}}-\tau_{\mathrm{bx}}}{\rho \mathrm{H}_{\mathrm{k}}}\end{array}$ & $\begin{array}{l}\text { Momentum equation in } \mathrm{x} \text { direction } \\
\frac{\partial \mathrm{q}_{\mathrm{x}}}{\partial \mathrm{t}}+\beta\left[\frac{\partial \mathrm{Uq}_{\mathrm{x}}}{\partial \mathrm{x}}+\frac{\partial \mathrm{vq}_{\mathrm{x}}}{\partial \mathrm{y}}\right]=-\mathrm{gH} \frac{\partial \zeta}{\partial \mathrm{x}}+ \\
+\frac{\partial}{\partial \mathrm{x}}\left[\mathrm{v}_{\mathrm{t}}\left(\frac{\partial \mathrm{q}_{\mathrm{x}}}{\partial \mathrm{x}}+\frac{\partial \mathrm{q}_{\mathrm{x}}}{\partial \mathrm{x}}\right)\right]+ \\
+\frac{\partial}{\partial \mathrm{y}}\left[\mathrm{v}_{\mathrm{t}}\left(\frac{\partial \mathrm{q}_{\mathrm{x}}}{\partial \mathrm{y}}+\frac{\partial \mathrm{q}_{\mathrm{y}}}{\partial \mathrm{x}}\right)\right]+\frac{\tau_{\mathrm{sx}}-\tau_{\mathrm{bx}}}{\rho}\end{array}$ \\
\hline $\begin{array}{l}\text { Momentum equation in y direction } \\
\frac{\partial \mathrm{v}}{\partial \mathrm{t}}+\mathrm{u} \frac{\partial \mathrm{v}}{\partial \mathrm{x}}+\mathrm{v} \frac{\partial \mathrm{v}}{\partial \mathrm{y}}+\mathrm{w} \frac{\partial \mathrm{v}}{\partial \mathrm{z}}=-\mathrm{g} \frac{\partial \zeta}{\partial \mathrm{y}}+ \\
+\frac{\partial}{\partial \mathrm{x}}\left[\mathrm{v}_{\mathrm{t}} \frac{\partial \mathrm{v}}{\partial \mathrm{x}}\right]+\frac{\partial}{\partial \mathrm{y}}\left[\mathrm{v}_{\mathrm{t}} \frac{\partial \mathrm{v}}{\partial \mathrm{y}}\right]+ \\
+\frac{\partial}{\partial \mathrm{z}}\left[\mathrm{v}_{\mathrm{t}} \frac{\partial \mathrm{v}}{\partial \mathrm{z}}\right]+\frac{\tau_{\mathrm{sy}}-\tau_{\mathrm{by}}}{\rho \mathrm{H}_{\mathrm{k}}}\end{array}$ & $\begin{array}{l}\text { Momentum equation in y direction } \\
\frac{\partial \mathrm{q}_{\mathrm{y}}}{\partial \mathrm{t}}+\beta\left[\frac{\partial U \mathrm{q}_{\mathrm{y}}}{\partial \mathrm{x}}+\frac{\partial \mathrm{vq}_{\mathrm{y}}}{\partial \mathrm{y}}\right]=-\mathrm{gH} \frac{\partial \zeta}{\partial \mathrm{y}}+ \\
+\frac{\partial}{\partial \mathrm{x}}\left[\mathrm{v}_{\mathrm{t}}\left(\frac{\partial \mathrm{q}_{\mathrm{y}}}{\partial \mathrm{x}}+\frac{\partial \mathrm{q}_{\mathrm{x}}}{\partial \mathrm{y}}\right)\right]+ \\
+\frac{\partial}{\partial \mathrm{y}}\left[\mathrm{v}_{\mathrm{t}}\left(\frac{\partial \mathrm{q}_{\mathrm{y}}}{\partial \mathrm{y}}+\frac{\partial \mathrm{q}_{\mathrm{y}}}{\partial \mathrm{y}}\right)\right]+\frac{\tau_{\mathrm{sy}}-\tau_{\text {by }}}{\rho}\end{array}$ \\
\hline $\begin{array}{l}\text { Momentum equation in } z \text { direction } \\
\frac{\partial p}{\partial z}=-\rho g\end{array}$ & None \\
\hline $\begin{array}{l}\text { Groundwater continuity equation } \\
\frac{\partial \mathrm{u}_{\mathrm{p}}}{\partial \mathrm{x}}+\frac{\partial \mathrm{v}_{\mathrm{p}}}{\partial \mathrm{y}}+\frac{\partial \mathrm{w}_{\mathrm{p}}}{\partial \mathrm{z}}+\mathrm{S}_{\mathrm{s}} \frac{\partial \mathrm{h}}{\partial \mathrm{t}}+\mathrm{Q}=0\end{array}$ & $\begin{array}{l}\text { Groundwater continuity equation } \\
\frac{\partial \mathrm{q}_{\mathrm{x}}}{\partial \mathrm{x}}+\frac{\partial \mathrm{q}_{\mathrm{y}}}{\partial \mathrm{y}}+\mathrm{n} \frac{\partial \mathrm{h}}{\partial \mathrm{t}}=0\end{array}$ \\
\hline $\begin{array}{l}\text { Darcy's law in } \mathrm{x} \text { direction } \\
\mathrm{u}_{\mathrm{p}}+\mathrm{K}_{\mathrm{xx}} \frac{\partial \mathrm{h}}{\partial \mathrm{x}}=0\end{array}$ & $\begin{array}{l}\text { Darcy's law in } x \text { direction } \\
\mathrm{q}_{\mathrm{x}}+\mathrm{KH} \frac{\partial \mathrm{h}}{\partial \mathrm{x}}=0\end{array}$ \\
\hline $\begin{array}{l}\text { Darcy's law in y direction } \\
\mathrm{v}_{\mathrm{p}}+\mathrm{K}_{\mathrm{yy}} \frac{\partial \mathrm{h}}{\partial \mathrm{y}}=0\end{array}$ & $\begin{array}{l}\text { Darcy's law in y direction } \\
\mathrm{q}_{\mathrm{y}}+\mathrm{KH} \frac{\partial \mathrm{h}}{\partial \mathrm{y}}=0\end{array}$ \\
\hline $\begin{array}{l}\text { Darcy's law in z direction } \\
\mathrm{w}_{\mathrm{p}}+\mathrm{K}_{\mathrm{zz}} \frac{\partial \mathrm{h}}{\partial \mathrm{z}}=0\end{array}$ & None \\
\hline
\end{tabular}

where $C_{s}$ is the air-water resistance coefficient, $\rho_{\alpha}\left[M / L^{3}\right]$ is the air density, $W_{x}$ and $W_{y}[L / T]$ are the wind velocity components in the $x$ and $y$ direction, respectively, $C\left[L^{1 / 2} / T\right]$ is the Chezy bed roughness and $u_{b}$ and $v_{b}[L / T]$ are the bed velocity components in the $x$ and $y$ directions, 
The assumption of hydrostatic pressure distribution for the surface water body leads to the following expression for the pressure and the piezometric head for the surface water body cells:

$$
\begin{aligned}
& \frac{\mathrm{p}}{\rho \mathrm{g}}=\mathrm{z}_{\mathrm{s}}-\mathrm{z}=\mathrm{z}_{\mathrm{si}}+\zeta-\mathrm{z} \\
& \mathrm{h}=\mathrm{z}+\left(\mathrm{z}_{\mathrm{si}}+\zeta-\mathrm{z}\right)=\mathrm{z}_{\mathrm{si}}+\zeta=\mathrm{z}_{\mathrm{s}}
\end{aligned}
$$

i.e the piezometric head is equal to the surface water level $z_{s}[L]$ and the terms $\partial \zeta / \partial t$, $\partial \zeta / \partial \mathrm{x}$ and $\partial \zeta / \partial \mathrm{y}$ in equations (2a), (3a) and (5a) can be replaced by the terms $\partial \mathrm{h} / \partial \mathrm{t}$, $\partial \mathrm{h} / \partial \mathrm{x}$ and $\partial \mathrm{h} / \partial \mathrm{y}$ respectively. In the resulting equations (1a) to (9a) the unknowns are: the 6 surface and groundwater velocity components $\left(u, u_{p}, v, v_{p}, w\right.$ and $\left.w_{p}\right)$, the pressure $\mathrm{p}$ and the piezometric head $\mathrm{h}$.

Equations (1a) to (9a) are solved explicitly using a central finite difference scheme in space. An example of the computational, staggered and orthogonal grid used in the computations is shown in Figure 1; the velocities are calculated at the faces and piezometric heads at the centre of the finite volumes.

The solution method is the following:

1) In the computational domain surface water and groundwater or porous cells are defined using the water depth (dep) as the identification variable. A non-zero water depth $(d e p \neq 0)$ is assigned to all surface water cells and a zero water depth $(d e p=0)$ to porous cells.

2) Initial values for the piezometric head $(h)$ are assigned to all model cells. Cells falling outside the model area are assigned a '-2' constant piezometric head.

3) Equations (2a), (3a) and (1a) are solved for surface water cells, or equations (7a) to (9a) are solved for porous cells, to determine the corresponding surface or porous velocity components. At the interface between the surface and the groundwater body, the velocities are calculated using equations (7a) to (9a). Both confined and unconfined aquifers can be simulated.

4) Equation (5a) or (6a) is used to calculate the piezometric head (h) for the surface water or porous cells.

5) When the piezometric head of a porous cell, calculated at a time step, is less or equal to its bottom elevation, the cell converts to 'dry' and is assigned a zero piezometric head. The approach adopted for the rewetting of a 'dry' cell is similar to the one described in McDonald et al [14]. A 'dry' porous cell can be rewetted if the piezometric head in one of the four adjacent cells equals or exceeds a user-specified wetting threshold at the end of a time step.

As shown in Figure 1, the ISGM can take into account groundwater areas adjacent and below the surface water body. If groundwater cells below the surface water body become unsaturated, seepage is still calculated based on the fact that the surface water cells remain saturated, so that the pressure sensed on the lower surface of the surface water's body bed is atmospheric (taken as zero in the model formulation). Thus, the piezometric head at the bottom of the surface water body cell is simply the elevation at that point that is the elevation of the top of the groundwater cell. The same approach is used, when groundwater cells, which are overlaid by other groundwater cells, become partly unsaturated. This is only a first approximation and it is envisaged that equations for variably saturated flow will be taken into account in future versions of the ISGM. 


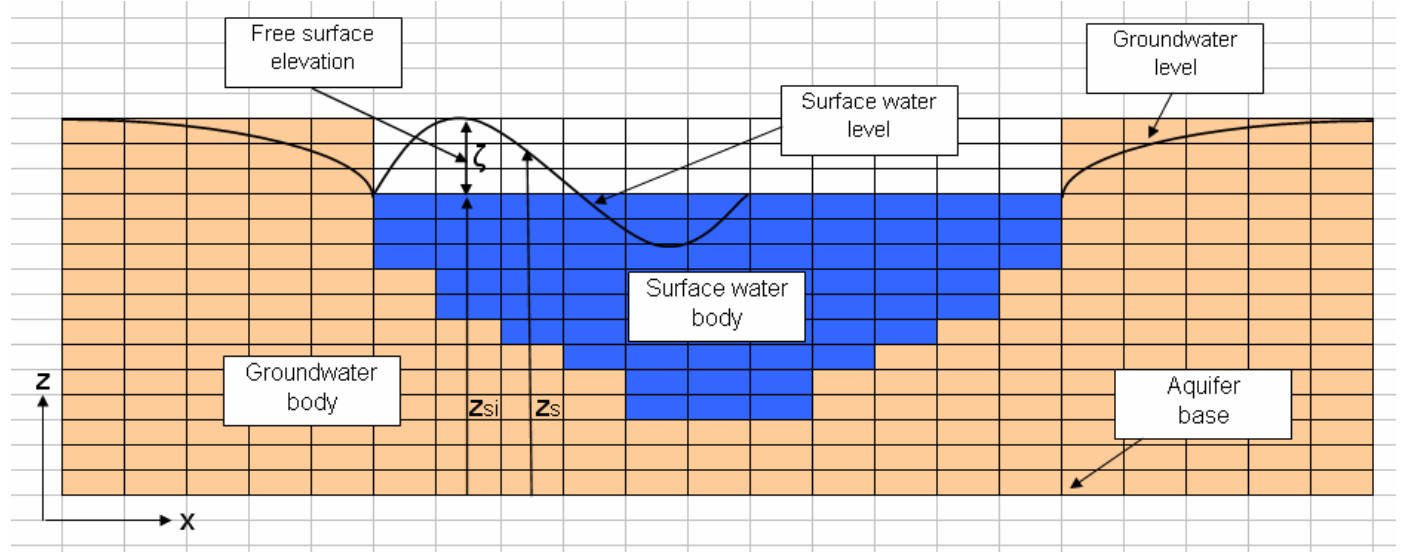

Figure 1. An example of the computational domain of the NTUA ISGM

\subsection{The solution method for the CU ISGM}

The CU ISGM considers unconfined groundwater flows with the horizontal flow approximation so the piezometric head $\mathrm{h}$ is equal to the groundwater free surface level, which depends on the free surface elevation $\zeta$. Thus, the terms $\partial \mathrm{h} / \partial \mathrm{t}, \partial \mathrm{h} / \partial \mathrm{x}$ and $\partial \mathrm{h} / \partial \mathrm{y}$ in equations $(6 b)$ to $(8 b)$ can be replaced by the terms $\partial \zeta / \partial t$, $\partial \zeta / \partial x$ and $\partial \zeta / \partial y$ respectively. In the resulting equations (1b) to (8b) the unknowns are: the flow per unit width $\mathrm{q}_{\mathrm{x}}$ and $\mathrm{q}_{\mathrm{y}}$ in the $\mathrm{x}$ and $\mathrm{y}$ directions respectively and the free surface elevation $\zeta[L]$.

Equations (1b) to (8b) are solved using the ADI (Alternating Direction Implicit) method; this splits the equations into ' $x$ ' and ' $y$ ' sweeps for each of two half time steps. Thus, the $x$ direction equations are solved for the first half time step, and then they are used as explicit solutions, while solving the y direction equations for the second half time step. This method was firstly proposed by Peaceman and Rachford [15].

After discretisation, equations ( $1 b)$ to $(8 b)$ can be reduced to the following:

Continuity equation $-x$ direction sweep

$A q_{x i-1}^{n+1}+B \zeta_{i}^{n+1 / 2}+C q_{x i}^{n+1}=D_{x}$

Continuity equation - y direction sweep

$A q_{y j-1}^{n+3 / 2}+B \zeta_{i}^{n+1}+C q_{y j}^{n+3 / 2}=D_{y}$

Momentum equation $-\mathrm{x}$ direction sweep

$E \zeta_{i}^{n+1 / 2}+F q_{x i}^{n+1}+G \zeta_{i+1}^{n+1 / 2}=H_{x}$

Momentum equation - y direction sweep

$E \zeta_{j}^{n+1}+F q_{y j}^{n+3 / 2}+G \zeta_{j+1}^{n+1}=H_{y}$

Subscripts "i" and "j" indicate the cell and superscript " $n$ " indicates the time step. Where the model simulates groundwater, the coefficients $A, B, C$ etc are derived from the groundwater equations instead of the surface shallow water equations and this is denoted by an asterix “*'. Hence, 16 coefficients $\left(A, B, C, D, E, F, G, H\right.$ and $A^{*}, B^{*}, C^{*}, D^{*}, E^{*}, F^{*}$, $\mathrm{G}^{*}, \mathrm{H}^{*}$ ) are obtained that define the governing equations, the first set derived from surface water equations and the second from the groundwater equations. The solution method and underlying equation structure is the same for both, so the model can solve both surface and groundwater areas continuously. 
In Figure 2 an example of the computational domain is shown, which refers to two surface water bodies separated by a 'sand bar'.

In the computational domain a cell identification index (cind) is used to define different types of cells: cind=1 for potentially surface water cells, cind=7 for groundwater or porous cells, cind $=2$ for tidal boundary cells and cind $=0$ for the cells, which are excluded from the computational domain. Potentially surface water cells can flood and dry as the water elevation changes. The model simulates surface and groundwater areas at the same time simply by switching from the surface water to the groundwater equations coefficients depending on whether it identifies a surface water $(\operatorname{cind}=1)$ or a groundwater $(\operatorname{cind}=7)$ cell.

Figure 3 shows a schematic for the interface between surface water and groundwater cells. Due to the 2-D nature of the model, at present it is only capable of simulating vertical boundaries between the surface water and groundwater. In the ISGM, areas beneath the surface water body are not included in the model. An arbitrary baseline at the deepest part of the surface water body is taken as the base of the groundwater regime. It is planned to extend the model by adding another pseudo layer underneath the surface water areas, to take into account vertical seepage beneath the surface water body allowing simulation of similar situations to that in Figure 1.

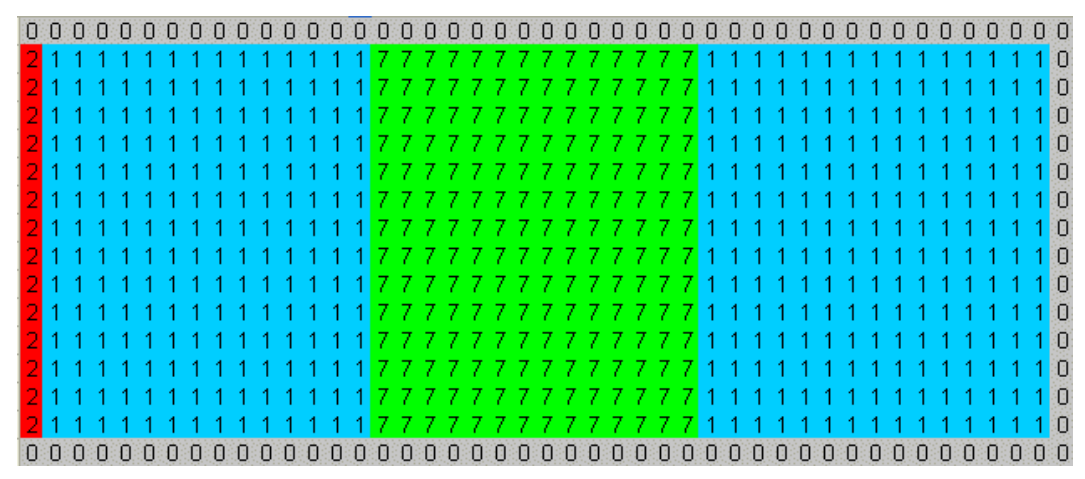

Figure 2. An example of the computational domain of the CU ISGM

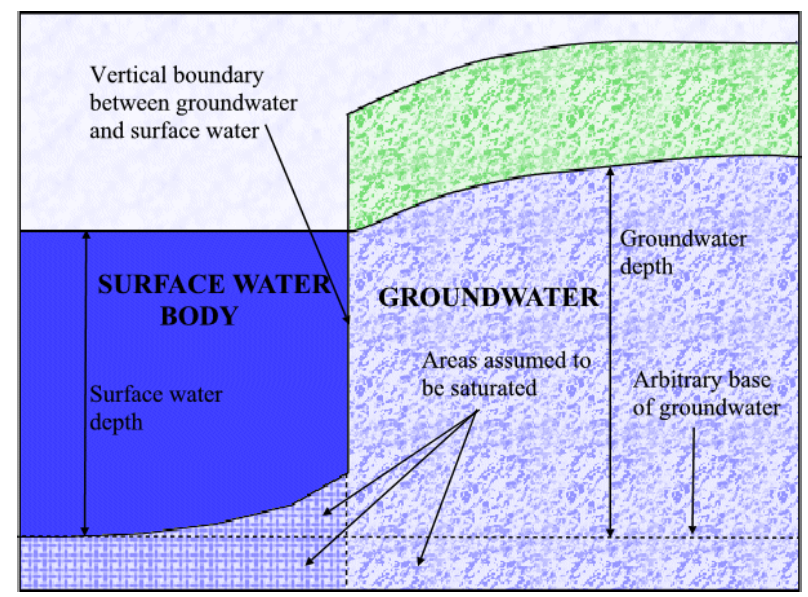

Figure 3. Surface water-groundwater schematic

\section{APPLICATION EXAMPLES}

\subsection{Test case I}

The NTUA ISGM has been used to simulate the transient hydraulic interaction between a partially penetrating river and a confined aquifer, which is shown in Figure 4. 
This example has been chosen to demonstrate the need to use an ISGM to predict the transient surface and groundwater flow in 3 dimensions; such a case cannot be predicted satisfactorily using traditional separate surface water or groundwater models.

The aquifer has the following dimensions: thickness $H_{a}=10 \mathrm{~m}$, length $L_{a}=80 \mathrm{~m}$ and width $\mathrm{W}_{\mathrm{a}}=80 \mathrm{~m}$. It is homogeneous and isotropic with impermeable top and bottom and has a hydraulic conductivity equal to $K_{a}=0.0005 \mathrm{~m} / \mathrm{s}$. The river has a width of $W_{r}=20 \mathrm{~m}$ and is in direct connection with the aquifer. The river penetration ratio into the aquifer is equal to $\mathrm{H}_{\mathrm{r}} / \mathrm{H}_{\mathrm{a}}=40 \%$. Constant head boundaries $h_{w}$ and $h_{e}$ are specified at the west and east boundaries of the aquifers, respectively. The north and south boundaries of the aquifer are considered impermeable.

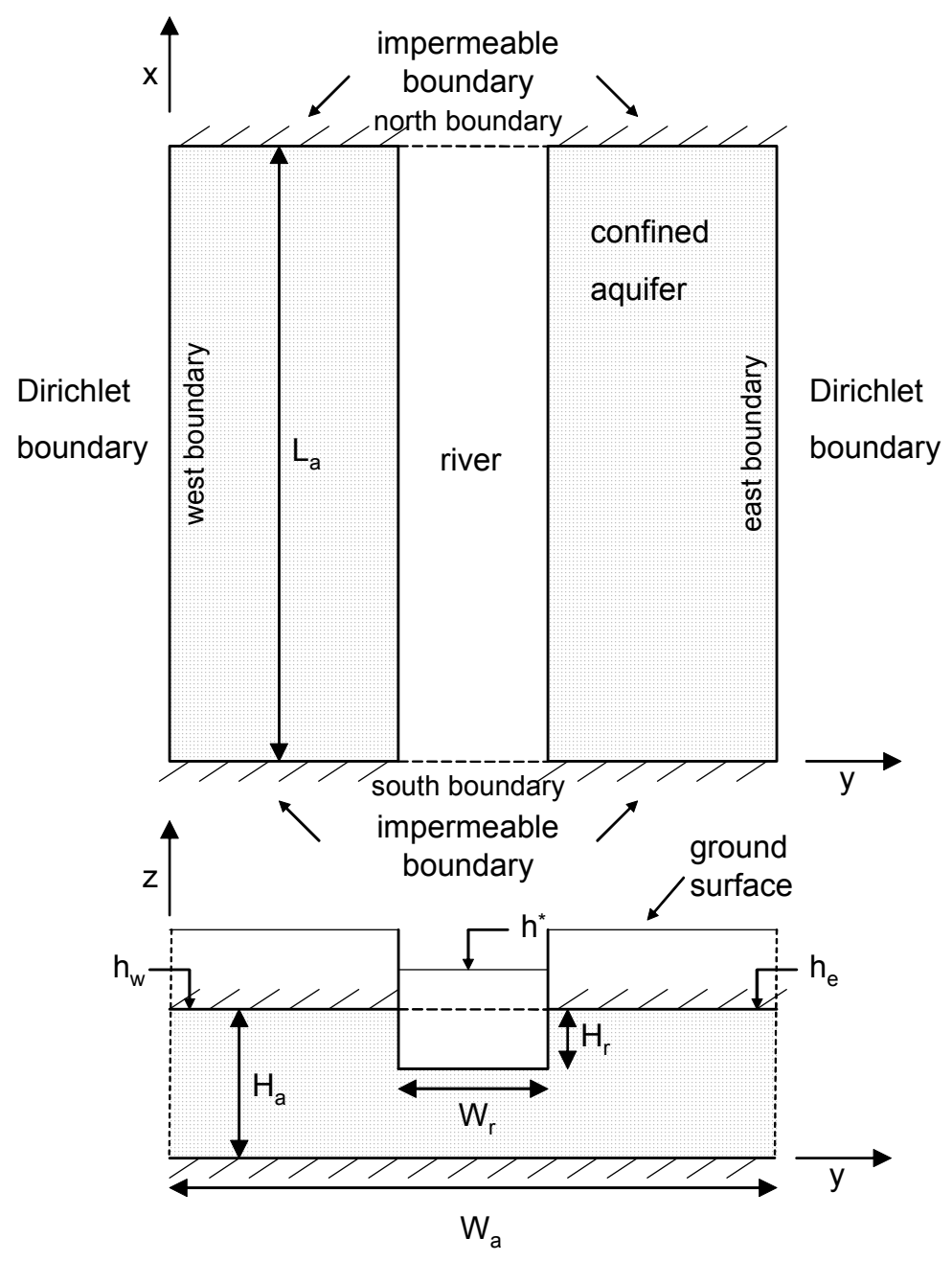

Figure 4. Definition sketch: Surface water-groundwater interaction in the horizontal and vertical planes

The river and the aquifer are initially in hydraulic equilibrium, i.e. the piezometric head of the river $h^{*}$ is equal to $h_{w}$ and $h_{e}\left(h_{w}=h^{*}=h_{e}\right)$. A sinusoidal passing flood wave is assumed at the south boundary of the river, while the north boundary is considered as 'outflow'. The flood wave has a peak of $1.0 \mathrm{~m}$ and lasts for $2 \mathrm{hrs}$.

In Figure 5 the temporal variation of the piezometric head for a cross-section of the domain in the $y$ direction at $x=39 \mathrm{~m}$ (middle of the domain) and $z=9.5 \mathrm{~m}$ (top of the domain) is shown using (a) FLOW-3DL and (b) the ISGM. 
When FLOW-3DL is used, i.e. the groundwater areas are not taken into account (see Fig. $5 a)$, the piezometric head in the river, i.e. the surface water level, rises from the initial $10.0 \mathrm{~m}$ to $10.4 \mathrm{~m}$ at $\mathrm{t}=0.5 \mathrm{hrs}$ and to $10.6 \mathrm{~m}$ at $\mathrm{t}=1.0 \mathrm{hrs}$ during the rising part of the flood wave. During the recession part of the wave the surface water level falls to $10.49 \mathrm{~m}$ at $\mathrm{t}=1.5 \mathrm{hrs}$ and to $10.07 \mathrm{~m}$ at $\mathrm{t}=2.0 \mathrm{hrs}$. It takes approximately $4 \mathrm{hrs}$ for the surface water level to return to the initial water level of $10 \mathrm{~m}$.

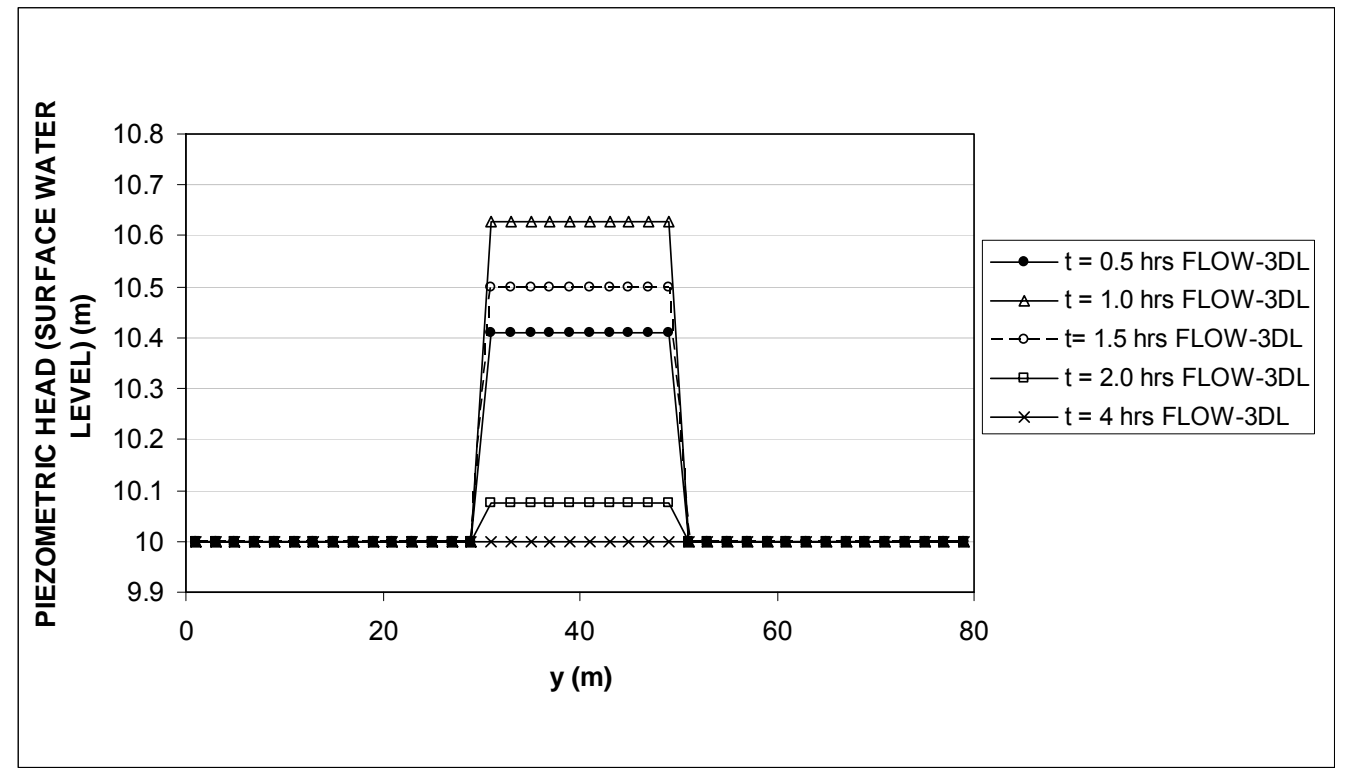

(a)

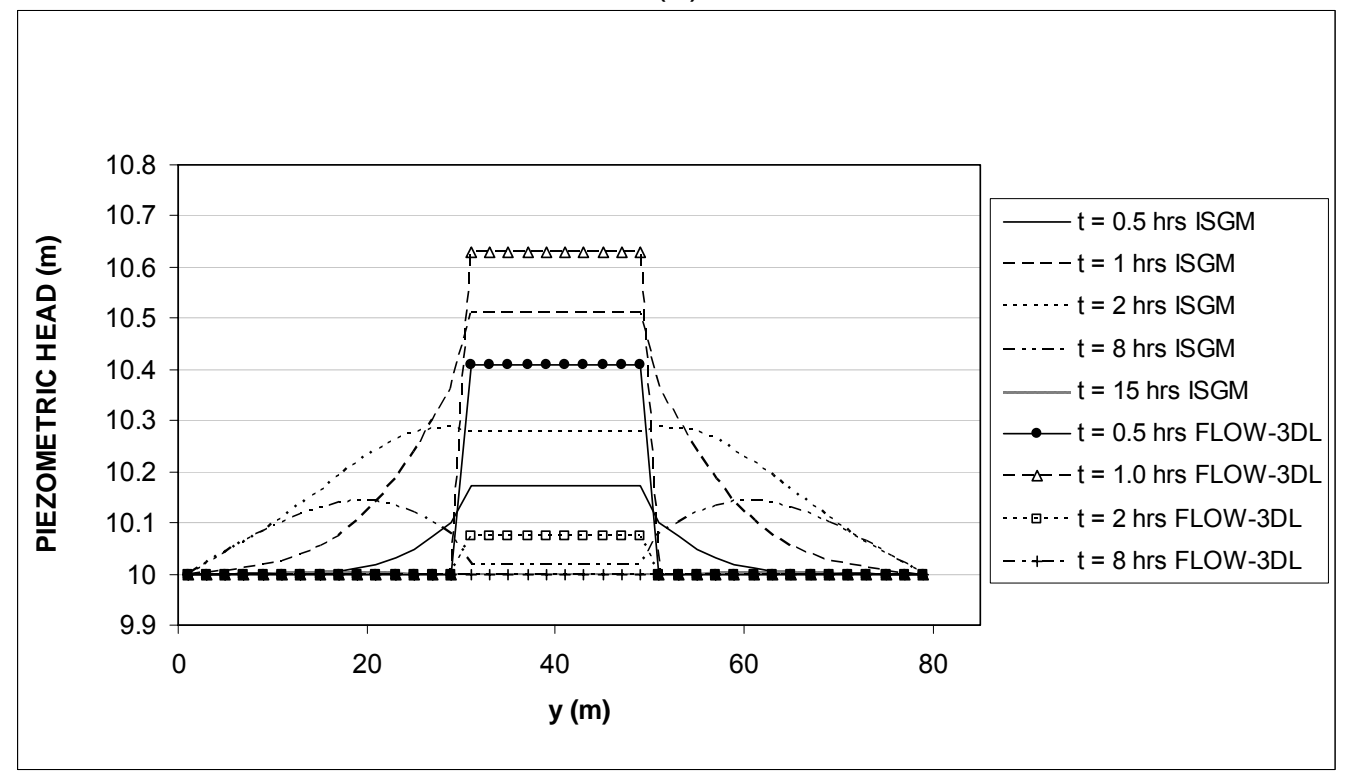

(b)

Figure 5. Temporal variation of the piezometric head using (a) FLOW-3DL and (b) the NTUA ISGM

When the ISGM is used, calculated surface water levels are very different from the ones predicted using FLOW-3DL. As shown in Fig.5b, for $t=0.5 \mathrm{hrs}$ and $t=1 \mathrm{hrs}$ the flood wave still has not travelled far from the river-aquifer interface and the surface water level appears to be higher than piezometric heads in the aquifer, which means that the river 'feeds' the aquifer. Compared to the surface water levels predicted by FLOW-3DL the surface water levels predicted by the ISGM are $0.24 \mathrm{~m}$ and $0.12 \mathrm{~m}$ lower for $\mathrm{t}=0.5 \mathrm{hrs}$ and $t=1 \mathrm{hrs}$ respectively due to groundwater recharge from surface waters. At $t=2.0 \mathrm{hrs}$ 
the piezometric heads in the aquifer begin to be higher than the surface water level and the aquifer starts to 'feed' the river. For $t=8 \mathrm{hrs}$ the system has almost reached equilibrium with piezometric heads at the aquifer and the river almost equal to the initial piezometric heads. The ISGM for $t=2 \mathrm{hrs}$ and $\mathrm{t}=8 \mathrm{hrs}$ predicts surface water levels higher than the ones predicted by FLOW-3DL. This is due to the surface water recharge by the aquifer and shows that when the ISGM is not used the surface and groundwater levels are not correctly predicted.

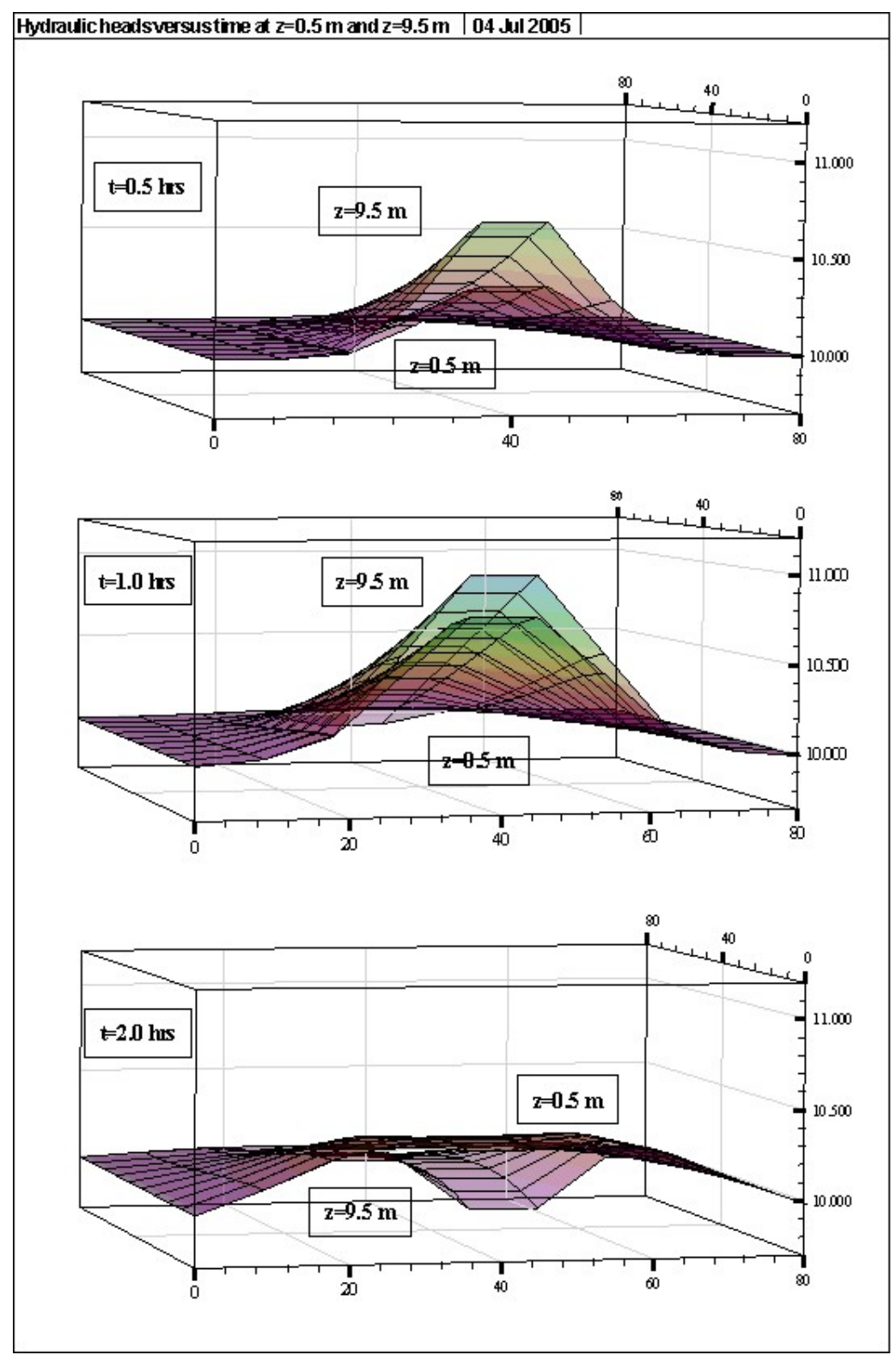

Figure 6. Piezometric surfaces for the aquifer top and base for $\mathrm{t}=0.5 \mathrm{hrs}, \mathrm{t}=1 \mathrm{hrs}$ and $\mathrm{t}=2 \mathrm{hrs}$ (dimensions are in $\mathrm{m}$ )

The 3-D character of the ISGM is shown in Figure 6, in which the piezometric heads in the $x$ - $y$ plane (piezometric surfaces) for the top $(z=9.5 \mathrm{~m})$ and the base $(z=0.5 \mathrm{~m})$ of the aquifer are plotted. The top of the aquifer intersects the river from $y=30 \mathrm{~m}$ to $\mathrm{y}=50$ $\mathrm{m}$. For $\mathrm{t}=0.5 \mathrm{hrs}$ and $\mathrm{t}=1 \mathrm{hrs}$, the piezometric heads in both the river and the aquifer rise and the piezometric surface at the top of the aquifer is higher than at the base of the aquifer, i.e. the river 'feeds' the aquifer. The opposite is true for $t=2.0 \mathrm{hrs}$ and the 
groundwater aquifer 'feeds' the river. This behaviour is due to the slow response of the aquifer, which stores water being later discharged back into the river.

\subsection{Test case II}

The CU ISGM has been used to simulate the transient hydraulic interaction of a complex water system consisting of two surface water bodies interconnected via a groundwater body (sand bar). The computational domain is shown in Figure 2 where ' 1 ' (cind=1) represents surface water body cells, ' 7 ' (cind=7) represents groundwater body cells and ' 2 ' (cind=2) represents a tidal boundary, which is assumed at the right surface water body.

In the CU ISGM porosity and permeability can be set and varied over the area of the model. In order to demonstrate the model operation for the present case, a relatively high permeability was used to allow quick interactions between the water bodies.

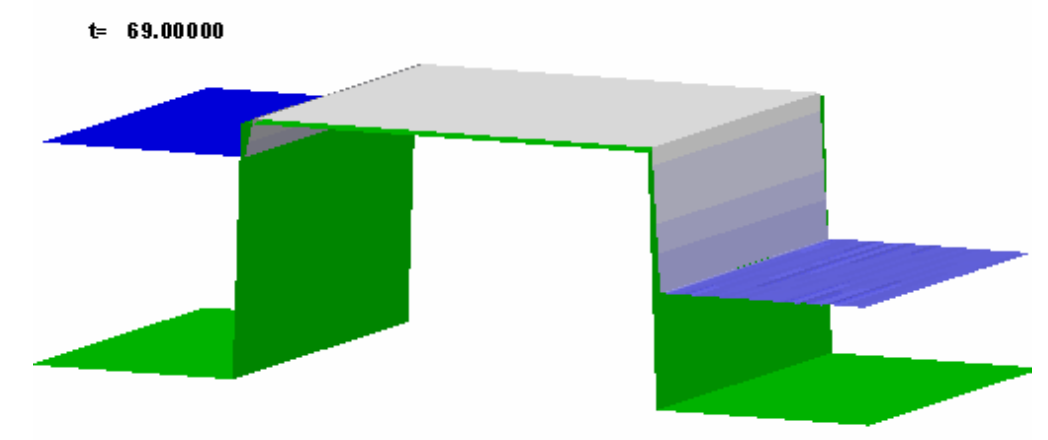

(a)

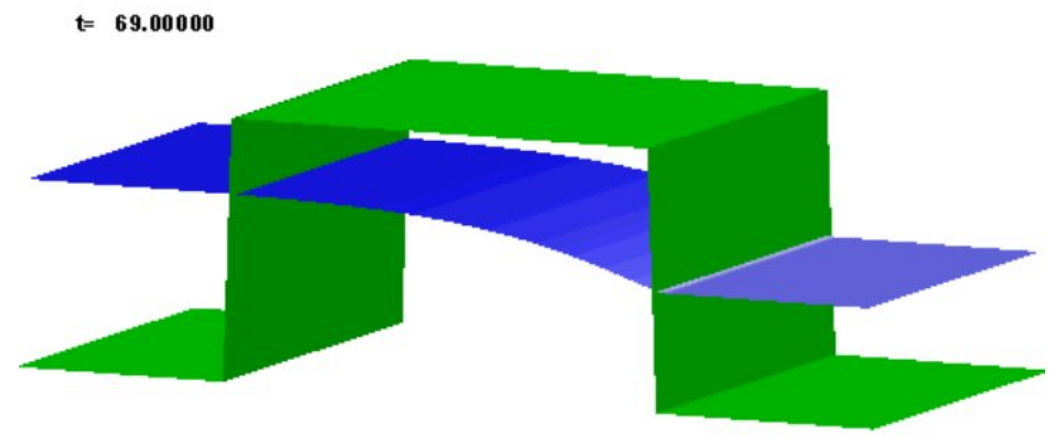

(b)

Figure 7. Water levels for $t=69$ min using (a) DIVAST and (b) the CU ISGM

Computations have been performed using (a) DIVAST and (b) the CU ISGM. In Figure 7 the water levels for the whole domain at $t=69 \mathrm{~min}$ are shown. When DIVAST is used, i.e. the groundwater area is not taken into account (see Figure 7a), a very shallow water depth is assumed over the groundwater area (sand bar) and so the left surface water body remains unaffected by the tide at the right surface water body. When the ISGM is used (see Figure 7b) flow is allowed to continue from the one surface water body into the other through the sand bar and the left surface water body is affected by the tide imposed on the right surface water body.

\subsection{Test case III}

Both ISGMs have been applied to a common test case. This case is an experimental setup, which has been constructed at the Hyder Hydraulics Laboratory of Cardiff University. The laboratory data, to be collected in the experiments, will be used for the calibration and the verification of the two ISGMs. 


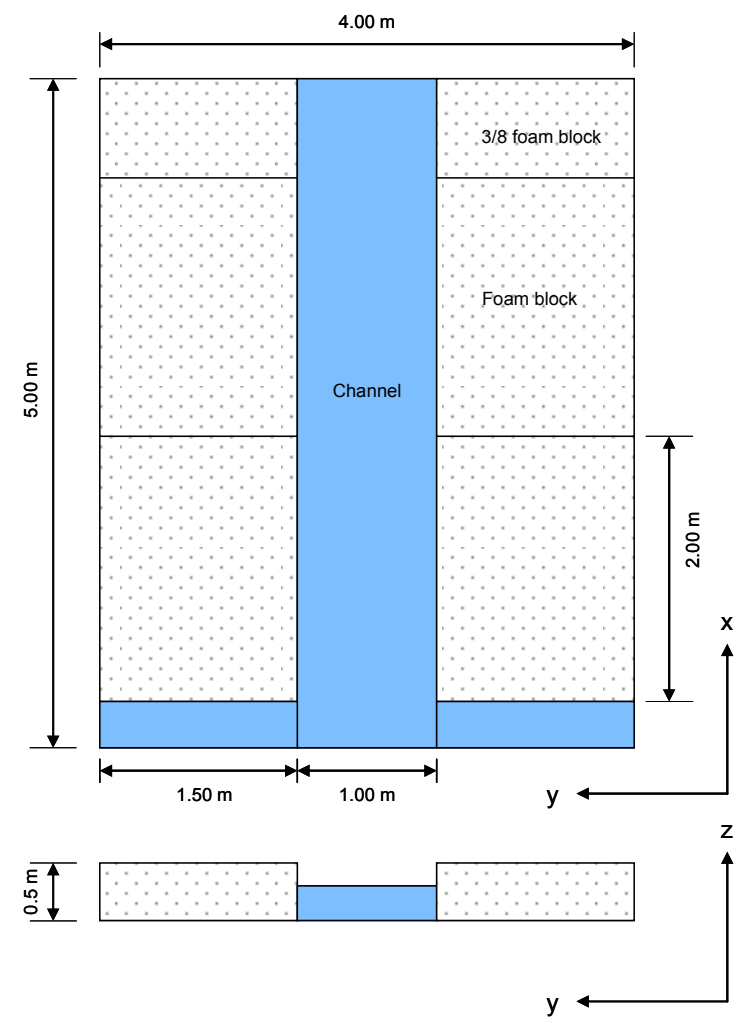

Figure 8. Schematic diagram of the experimental set-up at the Hyder Hydraulics Laboratory of Cardiff University

Figure 8 shows a sketch of the experimental set-up, which consists of a channel that fully penetrates an aquifer. A novel approach has been applied for the construction of the aquifer, which involves the use of porous permeable foam with a density of 60 ppi (pores per inch). The foam is in the form of blocks. Each foam block has the following dimensions: length $L_{f}=2 \mathrm{~m}$, width $W_{f}=1.5 \mathrm{~m}$ and thickness $H_{f}=0.5 \mathrm{~m}$. At each side of the channel 2 and $1 / 2$ foam blocks have been used to represent the aquifer. The channel has a width of $1.00 \mathrm{~m}$. The total dimensions of the experimental setup are the following: length $L_{e}=5 \mathrm{~m}$, width $W_{e}=4 \mathrm{~m}$ and thickness $H_{e}=0.5 \mathrm{~m}$. A conservative tracer (Rhodamine WT) will be used to study the interaction between the channel and the aquifer.

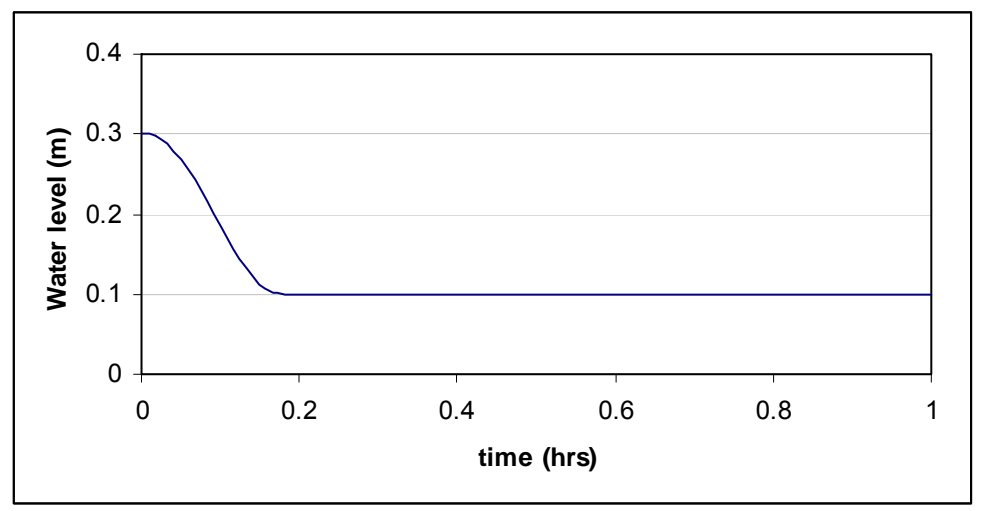

Figure 9. Assumed variation of the channel water level at the south boundary 

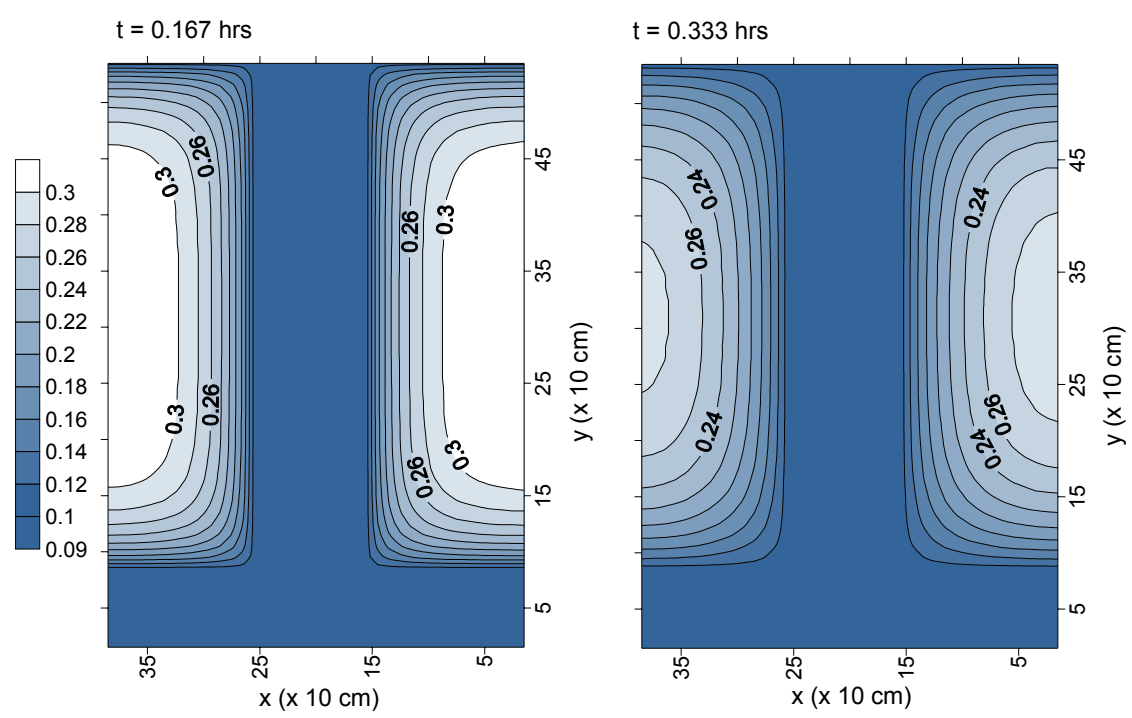

(a)

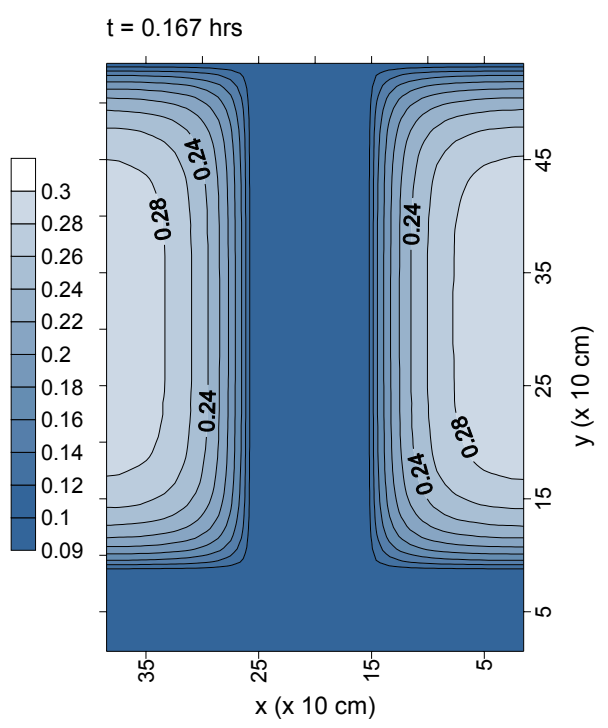

$\mathrm{t}=0.333 \mathrm{hrs}$

(b)

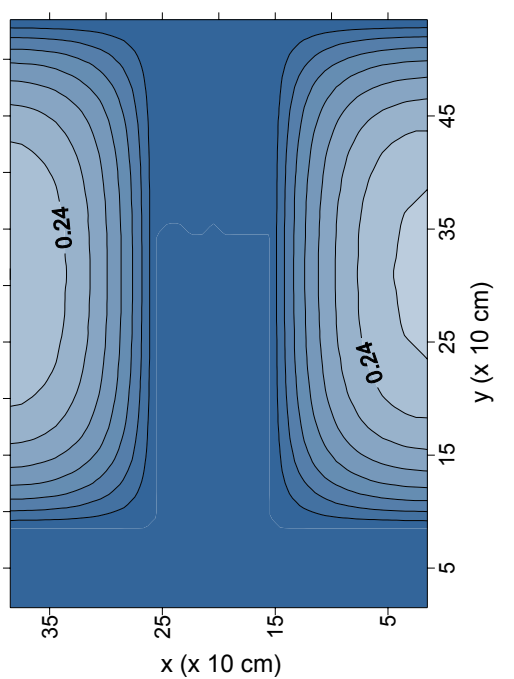

Figure 10. Calculated water levels using (a) the NTUA ISGM and (b) the CU ISGM

The channel and the aquifer are initially in hydraulic equilibrium, i.e. the water level in the channel $h_{r}$ is equal to the water level in the aquifer $h_{a}$ and equal to $3 m\left(h_{r}=h_{a}=3 m\right)$. Part of a sinusoidal tidal wave is assumed at the south boundary of the channel $(x=0 \mathrm{~m})$, while the north boundary $(x=5 \mathrm{~m})$ is considered as 'closed'. The tidal wave causes the water level at the south boundary of the channel to reduce from $0.3 \mathrm{~m}$ to $0.1 \mathrm{~m}$ in approximately 11 minutes as shown in Figure 9.

Figure 10 shows the calculated water levels in the experimental setup in the $x-y$ plane for $\mathrm{t}=0.167 \mathrm{hrs}$ and $\mathrm{t}=0.333 \mathrm{hrs}$ using (a) the NTUA ISGM and (b) the CU ISGM. As the water level in the channel reduces from $0.3 \mathrm{~m}$ to $0.1 \mathrm{~m}$, water flows from the aquifer into the channel causing the water levels in the groundwater to fall gradually. The NTUA ISGM predicts that the maximum water level in the aquifer reduces from $0.3 \mathrm{~m}$ at $\mathrm{t}=$ $0.167 \mathrm{hrs}$ to $0.28 \mathrm{~m}$ at $\mathrm{t}=0.333 \mathrm{hrs}$. The CU ISGM respectively predicts a reduction of the maximum water level in the aquifer from $0.28 \mathrm{~m}$ at $\mathrm{t}=0.167 \mathrm{hrs}$ to $0.26 \mathrm{~m}$ at $\mathrm{t}=0.333$ hrs.

Figure 10 shows that the NTUA ISGM exhibits a slightly slower response of the water levels in the aquifers to channel water level changes, than the CU ISGM. 


\section{CONCLUSIONS AND FUTURE WORK}

Integrated modelling of surface and groundwater flows is an ongoing research at the Laboratory of Applied Hydraulics of the National Technical University of Athens and the Hydroenvironmental Research Centre of Cardiff University. Two Integrated Surface water - Groundwater flow Models (ISGM) have been developed within the framework of the bilateral project "Development and Application of an Integrated Hydro-informatics Software Tool for Flow and Pollutant Interactions between the Coastal Zone and Neighbouring Wetlands" between Greece and Great-Britain, to investigate surface water-groundwater interactions. The NTUA ISGM consists of a 3-D surface water flow sub-model (FLOW3DL) and a 3-D saturated groundwater flow sub-model. The CU ISGM is based on the 2D surface water model DIVAST, which has been extended to include 2-D saturated groundwater flow. Both models use the finite difference method and orthogonal grids.

The ISGMs have been applied to two simple cases and their results have been compared with computations using the surface water models FLOW-3DL and DIVAST to demonstrate the need to use ISGMs for accurate and satisfactory calculations. Furthermore, the results of the two ISGMs are compared for a simulation of the flow in an experimental set-up, consisting of two aquifers, which are interconnected via a channel. The two ISGMs show a similar behaviour; the NTUA ISGM exhibits a slightly slower response of aquifer water levels to the water level changes in the channel than the $\mathrm{CU}$ ISGM. It is planned to add a vertical seepage facility to the CU ISGM, in order to be able to compare results for the situation in Figure 1.

Both ISGMs require calibration with field and/or laboratory data and extensive testing prior to their use in actual cases. Very few laboratory data for model calibration and verification exist in the literature. Laboratory measurements are currently in progress at Hyder Hydraulics Laboratory of Cardiff University. A series of experiments will be performed in the beginning of 2006.

In their current versions, the two ISGMs are able to calculate the groundwater piezometric surface in porous media, which are close to the surface water domain, as they use a common time step for both surface and groundwater areas. Furthermore, the ISGMs make no provision for simulating the unsaturated or soil water zone in groundwater. Future versions of the models will address these areas.

\section{ACKNOWLEDGMENTS}

Part of this research has been supported by the General Secretariat for Research \& Technology: PENED 03D395 and Joint Research and Technology Programmes. The UK work is supported by the Natural Environment Research Council ref. NER/S/A/2003/11216 and the British Council (Project ATH/882/2/GSRT).

\section{REFERENCES}

1. Swain E.D. and Wexler E.J. (1996), A coupled surface-water and ground-water flow model (Modbranch) for simulation of stream-aquifer interaction, Techniques of Water-Resources Investigations of the United States Geological Survey Book 6, Chapter A6.

2. Restrepo J.I., Montoya A.M. and Obeysekera J. (1998), A wetland simulation module for the MODFLOW ground water model, Ground Water, 36 (5), 764-770.

3. Jobson H.E. and Harbaugh A.W. (1999), Modifications to the Diffusion Analogy Surface-Water Flow Model (DAFLOW) for coupling to the Modular Finite-Difference Ground-Water Flow Model (MODFLOW), USGS, Open-File Report 99-217.

4. McDonald M.G. and Harbaugh A.W. (1988), A modular three-dimensional finite-difference ground water flow model, USGS Open File Report 83-875.

5. Vanderkwaak J.E. (1999), Numerical simulation of flow and chemical transport in integrated surface-subsurface hydrologic systems, PhD Thesis, University of Waterloo, Waterloo, Ontario. 
6. Panday S. and Huyakorn P.S. (2004), A fully coupled physically-based spatially distributed model for evaluating surface/subsurface flow, Advances in water Resources, 27, 361-382.

7. Bradford S.F. and Katopodes N.D. (1998), Nonhydrostatic model for surface irrigation, Journal of Irrigation and Drainage Engineering, 124 (4), 200-212.

8. Sokrut N. (2001), A distributed coupled model of surface and subsurface dynamics as a tool for catchment management, Licentiate Thesis Royal Institute of Technology, Stockholm, Sweden.

9. Graham N. and Refsgaard A. (2001), 'MIKE SHE: A distributed, physically based modelling system for surface water/groundwater interactions, In: Proceedings of 'MODLFOW 2001 and other modelling Odysseys', Seo B., Poeter E. and Zheng C. (eds), Golden, Colorado, pp. 321327.

10. Freeze R.A. (1972a), Role of subsurface flow in generating surface runoff: 1. Base flow contribution to channel flow, Water Resources Research, 8 (3), 609-623.

11. Stamou A.I., Noutsopoulos C., Pipilis K.G., Gavalaki E. and Andreadakis A. (1999), Hydrodynamic and Water Quality Modeling of Southern Evoikos Gulf- Greece, Global Nest the Int. J., $1(2), 5-15$.

12. Falconer R.A., Lin B., Wu Y. and Harris E. (2001), DIVAST Reference Manual', Manual, Environmental Water Management Research Centre, Cardiff University

13. Koutitas C. (1987), Three-Dimensional Models of Coastal Circulation: An Engineering Viewpoint, in 'Three-Dimensional Coastal Ocean Models', Coastal and Estuarine Sciences 4, Ed.: N.S. Heaps, American Geophysical Union, Washington, D.C.

14. McDonald M.G., Harbaugh A.W., Orr B.R. and Ackerman D.J. (1992), A method for converting no-flow cells for the USGS modular finite-difference ground-water flow model, USGS OpenFile Report 91-356.

15. Peaceman D.W. and Rachford-Jr. H.H. (1955), The numerical solution of parabolic and elliptic differential equations, Journal of the Society for Industrial and Applied Mathematics, 3, 28-41. 